\title{
The effect of body condition on metabolic changes associated with intake of food by the cow
}

\author{
BY J. A. BINES AND S. V. MORANT \\ National Institute for Research in Dairying, Shinfield, Reading RG2 $9 A T$
}

(Received 7 June 1982 - Accepted 6 January 1983)

\begin{abstract}
1. Changes in concentrations of metabolites in blood and rumen fluid were measured in cows when fat and when thin and when given hay and concentrates at a restricted level or ad lib.

2. When fed ad lib., cows consumed $24 \%$ more food when thin than when fat.

3. Concentrations in rumen fluid of acetate and propionate after feeding at both levels did not differ significantly between fat and thin cows.

4. Concentrations in blood of the lipogenic substrates acetate and 3-hydroxybutyrate did not differ between fat and thin cows after feeding, but glucose concentration fell more rapidly in thin cows especially when fed ad lib. Propionate rose more in thin cows than in fat cows when fed ad lib. Non-esterified fatty acids were higher in fat cows before feeding, but fell to similar levels to those in thin cows after feeding.

5. The results are interpreted as indicating a more rapid rate of fatty acid synthesis in adipose tissue of thin cows. This in turn tends to lower blood levels of fatty acid precursors and so enhance the rate of their absorption from the rumen. This in turn permits higher intake of food before short-term chemical regulators of intake start to operate.
\end{abstract}

It has been shown (Bines et al. 1969) that the non-lactating dairy cow given ad lib. access to a diet of hay and concentrates consumed approximately $23 \%$ more dry matter/d when thin, than when fat. The capacity of the reticulo-rumen did not appear to have limited intake of this diet in either fat or thin cows. It was concluded that control of food intake was by a predominantly metabolic mechanism and that it was flexible in its operation, permitting higher intakes by thin cows than by fat cows. Metabolites thought to be involved in the control of food intake in ruminants include acetate in the rumen and propionate in the liver (Forbes, 1980). Flexibility in this form of control may result from thin cows being able to tolerate higher concentrations of the metabolites thought to influence intake or, alternatively, may be due to a greater rate of utilization of these metabolites by thin cows. In a subsequent review paper (Bines, 1971) it was suggested that a more rapid utilization of lipogenic substrates by thin cows than by fat cows prevented the excessive accumulation of these substrates in the blood of thin cows. If this, in turn, resulted in accelerated absorption of volatile fatty acids (VFA) from the rumen of the thin cows, then a faster rate of fermentation could be accommodated without exceeding metabolite levels which may restrict intake. A similar idea has been discussed more recently by Forbes (1980). Evidence of increased utilization of lipogenic substrates with decreasing fatness has been provided in sheep by Orr (1977) but no information is available for the cow.

The objective of the present experiment was to measure concentrations of the major energy-yielding metabolites in the blood and rumen fluid of cows given high-concentrate diets, when the cows were thin and again when they were fat. Most measurements were made in cows fed ad lib., but some comparisons were also made on fat and thin cows given the same restricted level of feed. In addition, tritiated water was used to obtain an estimate of total body water in the two groups of cows, to act as an index of body condition. 


\section{EXPERIMENTAL \\ Procedure}

Six mature, non-lactating, Friesian cows, three in fat condition and three in thin, were given a ration of $3 \mathrm{~kg}$ hay $/ \mathrm{d}$ and $a \mathrm{~d} l i b$. access to concentrates for $5 \mathrm{~h}$ from 10.00 hours. Following the first treatment period, the condition of the two groups of cows was reversed over 5 months by giving the fat cows ad lib. access to barley straw and maintaining the hay and concentrate diet for the thin cows. In the second treatment period, all six animals were given $3 \mathrm{~kg}$ hay and $6 \mathrm{~kg}$ concentrates in one feed daily. In the third treatment period, before any further substantial change had occurred in the body-weight of the cows, the ad lib. ration used in the first period was reintroduced. Composition of the hay and concentrates used were similar to those given previously (Bines et al. 1969). Each period lasted $26 \mathrm{~d}$, the first $21 \mathrm{~d}$ being for equilibration of the cows on the experimental diet. On day 22 , a polyethylene cannula was established in one jugular vein. On days $23-25$, samples of rumen fluid were taken at 10.00 (prefeeding), 12.00, 14.00 and 16.00 hours and blood samples were taken at $09.00,10.00$ (prefeeding), 14.00, 15.00 and 16.00 hours. Sampling of blood and rumen fluid and their subsequent treatment and analysis were as described by Bines \& Davey (1978). Blood samples taken at 09.00 hours were analysed for glucose and non-esterified fatty acids (NEFA) only. On day 26, the rumen of the cows was emptied at 09.00 hours and the cows weighed whilst empty. Rumen contents were then replaced. To obtain an estimate of body water content, blood samples were taken at $10.00,15.00$ and 16.00 hours. Tritiated water was injected via the cannula immediately after the 10.00 hours blood sample was taken.

\section{Body water determination}

In a preliminary trial, it was demonstrated that equilibration of radioactivity from an injected dose of tritiated water was complete within $4 \mathrm{~h}$ in blood and rumen fluid and within $6 \mathrm{~h}$ in urine. The value remained unchanged for a further $4 \mathrm{~h}$ in blood and rumen fluid, thus sampling blood at 5 and $6 \mathrm{~h}$ after injection was adopted as a convenient means of sampling body water to measure tritium dilution. It had also been demonstrated that a single cannula could be used for injecting the tritiated water and for subsequent sampling if the cannula was flushed by injection of $25 \mathrm{ml}$ non-radioactive saline ( $9 \mathrm{~g}$ sodium chloride/l) after injection of the marker, and by withdrawing and discarding three $10 \mathrm{ml}$ portions of blood immediately before withdrawing the 15.00 hours sample.

The injected marker was $25 \mathrm{ml}$ saline containing approximately $1.25 \mathrm{mCi}$ tritiated water. The exact amount injected was determined by weighing the syringe used before and after injection. Water was obtained from the blood by vacuum distillation. Four $1 \mathrm{ml}$ portions of each sample were counted for radioactivity and efficiency determined by use of an external marker. Body water was determined by dividing the amount of radioactivity injected by the mean specific activity of body water after 5 and $6 \mathrm{~h}$.

\section{Statistical methods}

The experimental design was regarded as a split-plot with fat and thin condition as the main-plot treatments, and the diets as the sub-plot treatments. One treatment combination (fat condition of the restricted diet) is missing for three of the cows, and another combination (thin condition on the restricted diet) is missing for the other three cows. In the main analyses of variance for each variate there are therefore six missing values.

\section{RESULTS}

The mean empty-body-weights, body water contents and mean daily intakes of hay and concentrates for the two groups of cows are given in Table 1. 
Table 1. Mean empty-body-weight* $(\mathrm{kg})$, weight of rumen contents $(\mathrm{kg})$, body water content and mean dry matter intake ( $\mathrm{kg}$ ) of two groups of three cows in fat and thin condition, and on ad lib. and restricted levels of feeding

\begin{tabular}{|c|c|c|c|}
\hline $\begin{array}{l}\text { Period... } \\
\text { Level of feeding... }\end{array}$ & $\stackrel{1}{\text { Ad lib. }}$ & $\begin{array}{c}2 \\
\text { Restricted }\end{array}$ & $\begin{array}{c}3 \\
\text { Ad lib. }\end{array}$ \\
\hline \multicolumn{4}{|l|}{ Group 1} \\
\hline Condition & Fat & Thin & Thin \\
\hline Empty-body-wt & 742 & 487 & 534 \\
\hline Wt of rumen contents & $56 \cdot 3$ & 53.7 & 60.4 \\
\hline Body water $\%$ empty-body-wt) & $49 \cdot 1$ & - & $62 \cdot 8$ \\
\hline \multicolumn{4}{|l|}{ Intake } \\
\hline Hay & $2 \cdot 11$ & $2 \cdot 58$ & $2 \cdot 58$ \\
\hline Concentrates & $7 \cdot 12$ & $4 \cdot 59$ & 8.39 \\
\hline \multicolumn{4}{|l|}{ Group 2} \\
\hline Condition & Thin & Fat & Fat \\
\hline Empty-body-wt & 433 & 658 & 673 \\
\hline Wt of rumen contents & $63 \cdot 3$ & $59 \cdot 6$ & 59.9 \\
\hline Body water (\% empty-body-wt) & $72 \cdot 9$ & - & $49 \cdot 5$ \\
\hline \multicolumn{4}{|l|}{ Intake } \\
\hline Hay & $2 \cdot 57$ & $2 \cdot 26$ & $2 \cdot 33$ \\
\hline Concentrates & 8.49 & 3.87 & $5 \cdot 35$ \\
\hline \multicolumn{4}{|c|}{$\mathrm{SE}$ of differences between groups in the same period ( $4 \mathrm{df}$ ) } \\
\hline Empty-body-wt & 53.5 & $31 \cdot 2$ & 29.6 \\
\hline Wt of rumen contents & 6.23 & $7 \cdot 02$ & 8.89 \\
\hline Body water (\% empty-body-wt) & $3 \cdot 22$ & - & $2 \cdot 67$ \\
\hline \multicolumn{4}{|l|}{ Intake } \\
\hline Hay & 0.331 & 0.321 & 0.252 \\
\hline Concentrates & 0.676 & 0.460 & 0.720 \\
\hline
\end{tabular}

* Body-weight - weight of rumen contents.

The diet means for the concentrations and molar percentages of each VFA in rumen fluid before and after feeding when the cows were in fat and thin condition are given in Table 2 and Figs. 1 and 2. Before feeding, concentration of total VFA was higher in the fat cows than in the thin cows on the ad lib. diet $(P<0.05)$, but was very similar for fat and thin cows on the restricted diet. After feeding there was no difference between fat and thin animals on the ad lib. diet, but the restricted diet raised the concentration of total VFA in the thin animals $(P<0.05)$ less than in the fat animals.

High concentrations of acetate in fat animals on the ad lib. diet $(P<0.05)$ were largely responsible for the high levels of total VFA before feeding. A similar pattern was found in the concentrations of butyrate $(P<0 \cdot 1)$, but propionate concentrations did not differ between fat and thin cows before feeding. After feeding, propionate levels were higher and acetate levels lower in the thin cows on both diets, but neither of these differences attained significance $(P>0 \cdot 1)$.

The molar percentage of acetate was lower in the thin cows than in the fat cows after feeding both diets $(P<0 \cdot 1)$, although this difference was apparent before feeding only on the ad lib. diet $(P<0.05)$. Molar percentages of propionate were higher in the thin animals on both diets before and after feeding $(P<0 \cdot 1)$, the difference being larger on the ad lib. diet.

Rumen $\mathrm{pH}$ values before feeding (Table 2 and Fig. 1) were higher in thin animals, particularly on the restricted diet $(P<0.05)$. There was greater variation in $\mathrm{pH}$ levels after feeding and the difference between fat and thin animals remained significant only on the ad lib. diet $(P<0.05)$. 
Table 2. The concentrations ( $m$ mol/l) and molar percentages of volatile fatty acids (VFA) in the rumen of six cows in fat and thin condition and on ad lib. and restricted rations

\begin{tabular}{|c|c|c|c|c|c|c|c|}
\hline & \multirow{2}{*}{$\begin{array}{l}\text { Level of } \\
\text { feeding }\end{array}$} & \multicolumn{3}{|c|}{ Before feeding } & \multicolumn{3}{|c|}{ After feeding } \\
\hline & & Fat & Thin & SED & Fat & Thin & SED \\
\hline \multirow{2}{*}{$\begin{array}{r}\text { Total VFA } \\
(\mathrm{mmol} / \mathrm{l})\end{array}$} & Ad lib. & 75 & 57 & $4 \cdot 6^{*}$ & 131 & 131 & $14 \cdot 2$ \\
\hline & Restricted & 61 & 63 & $4.7 \dagger$ & 124 & 115 & 6.4 \\
\hline \multirow{2}{*}{$\begin{array}{l}\text { Acetate } \\
(\mathrm{mmol} / \mathrm{l})\end{array}$} & Ad lib. & 48 & 34 & $3 \cdot 6$ & 78 & 69 & $8 \cdot 3$ \\
\hline & Restricted & 40 & 39 & 2.7 & 74 & 63 & $4 \cdot 2$ \\
\hline \multirow{2}{*}{$\begin{array}{l}\text { Propionate } \\
(\mathrm{mmol} / \mathrm{l})\end{array}$} & Ad lib. & 13 & 14 & $1 \cdot 7$ & 25 & 36 & $5 \cdot 8$ \\
\hline & Restricted & 12 & 15 & 0.6 & 26 & 30 & 1.6 \\
\hline \multirow{2}{*}{$\begin{array}{l}\text { Butyrate } \\
(\mathrm{mmol} / \mathrm{l})\end{array}$} & Ad lib. & $9 \cdot 6$ & $6 \cdot 0$ & 1.83 & $20 \cdot 4$ & $17 \cdot 6$ & 1.97 \\
\hline & Restricted & $5 \cdot 3$ & $5 \cdot 1$ & $1 \cdot 54$ & $16 \cdot 7$ & $14 \cdot 2$ & $2 \cdot 27$ \\
\hline \multirow[t]{2}{*}{ Acetate $(\%)$} & Ad lib. & 64 & 59 & 1.8 & 60 & 52 & $2 \cdot 4$ \\
\hline & Restricted & 64 & 62 & 0.9 & 60 & 56 & 1.5 \\
\hline \multirow[t]{2}{*}{ Propionate $(\%)$} & Ad lib. & 17 & 24 & $2 \cdot 8$ & 18 & 27 & $2 \cdot 7$ \\
\hline & Restricted & 20 & 24 & $1 \cdot 2$ & 21 & 25 & 1.2 \\
\hline \multirow[t]{2}{*}{ Butyrate $(\%)$} & Ad lib. & $12 \cdot 3$ & $10 \cdot 4$ & $2 \cdot 14$ & 15.9 & $13 \cdot 4$ & 1.79 \\
\hline & Restricted & $9 \cdot 2$ & 7.8 & 1.34 & $13 \cdot 3$ & $12 \cdot 2$ & 1.45 \\
\hline \multirow{2}{*}{ Rumen pH } & Ad lib. & $6 \cdot 85$ & 6.94 & 0.054 & 6.03 & 5.64 & 0.125 \\
\hline & Restricted & 6.87 & $7 \cdot 02$ & 0.009 & 5.93 & 5.89 & 0.082 \\
\hline
\end{tabular}

SED, standard error of difference.

* SED between fat and thin cows on the same or different rations: based on the error mean squares for cows $\times$ conditions $(5 \mathrm{df})$ and cows $\times$ rations within conditions $(4 \mathrm{df})$.

$\dagger$ SED between diets, while the cows are in the same condition: based on the error mean square for cows $\times$ rations within conditions $(4 \mathrm{df})$.

Concentrations of 3-hydroxybutyrate (3HB) and acetate in blood plasma (Table 3 and Fig. 3) were unaffected by the condition of the animals either before or after feeding. Propionate and glucose levels before feeding were also unaffected although, after feeding, glucose levels were higher $(P<0 \cdot 1)$ on both diets when the animals were fat and propionate was higher $(P<0 \cdot 1)$ in thin cows on the ad lib. diet.

NEFA were present in higher concentrations in fat animals than in thin before feeding on both diets $(P<0.05)$. After feeding the concentrations fell less rapidly in the thin animals particularly on the ad lib. diet.

\section{DISCUSSION}

When the cows were fat and fed ad lib. the mean total daily intake of dry matter was $8.90 \mathrm{~kg}$ and this increased to $11.05 \mathrm{~kg}$ when the cows were thin. This represents a $24 \%$ increase in intake, almost identical to that observed previously on a similar diet (Bines et al. 1969). Intakes were always stable by the 12th day of each period at the latest and this was taken as an indication that the cows were in a steady-state at the times that measurements were made. By fixing the level of hay and offering concentrates ad lib., the forage: concentrate value of the diet changed with changing intake, and would have changed the rumen fermentation pattern (Broster et al. 1979). However, increased intakes of a diet of fixed composition also have the same effect (Broster et al. 1979) so that it would have been very difficult to avoid this change. It is recognized that ad lib. access for a restricted time period does not give an exact measure of the appetite of an animal in that some conditioning to this regimen may occur. Nevertheless, it seems likely that metabolic factors would still have played a major role in the control of intake of this kind of diet. During the period of restricted intake, the amount of food offered was less than that consumed by 

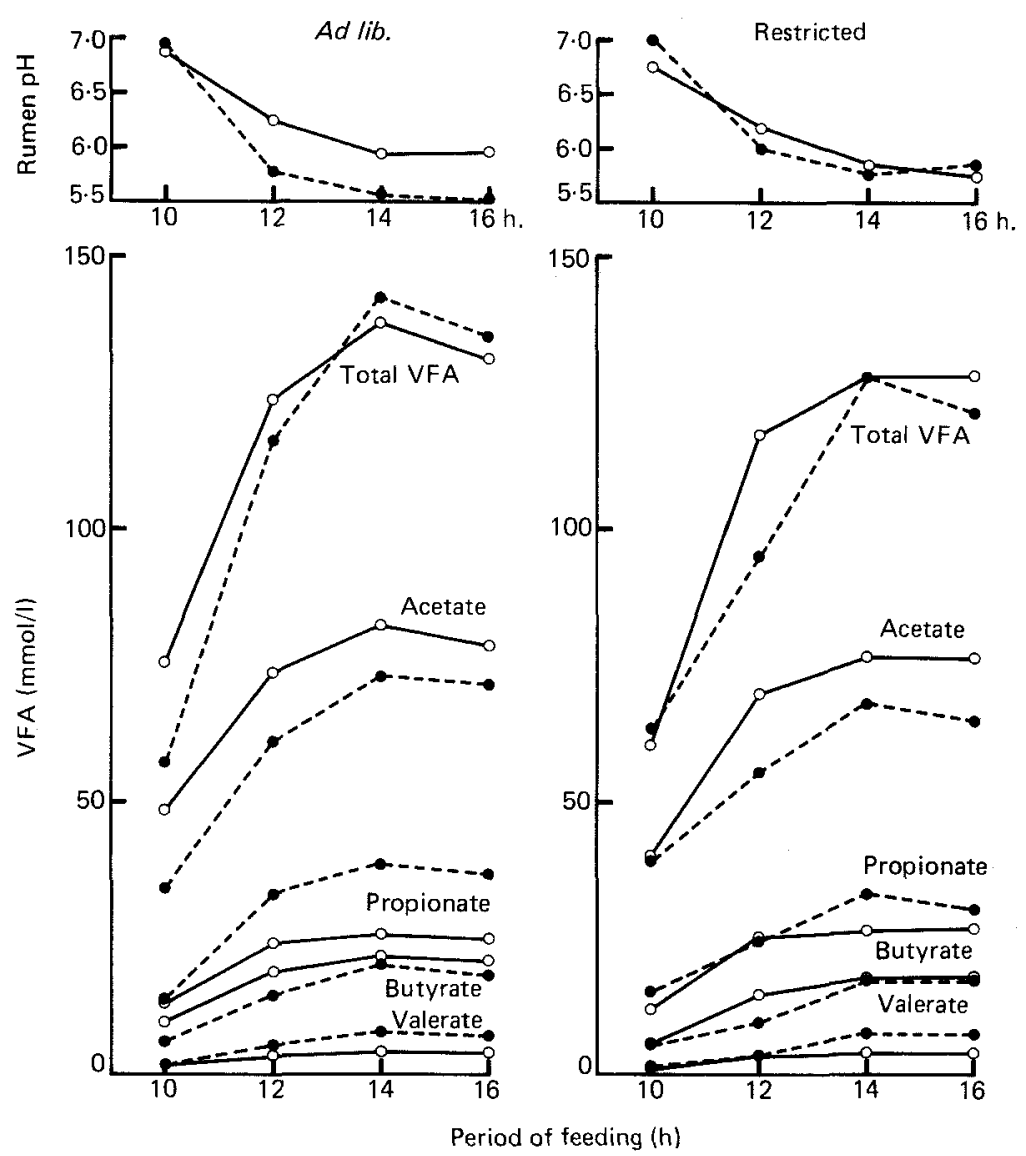

Fig. 1. The $\mathrm{pH}$ and concentrations (mmol/1) of volatile fatty acids (VFA) before and after feeding in the rumen of six cows in fat (-) and thin (---) condition and on ad lib. and restricted diets.

the fat cows when fed ad lib. However, small refusals by both groups of cows were somewhat larger when the cows were fat than when they were thin. Therefore, intakes of the two groups were not equal although the difference between them (approximately $11 \%$ ) was considerably less than when the animals were fed ad lib. During the period of ad lib. access to feed, the mean difference in weight between the cows when fat and when thin was $224 \mathrm{~kg}$.

It is likely that short-term mechanisms controlling intake of highly-digestible foods by ruminants are mediated by certain VFA and operate in or close to the rumen (Bines \& Davey, 1978). However, the utilization of VFA occurs largely in tissues and organs remote from the rumen. If the cows were able to utilize lipogenic substrates more rapidly when thin than when fat, it would be expected that concentrations of these substrates in both blood and rumen fluid would be lower in thin cows than in fat cows when both are fed at the same level, or similar when cows are fed ad lib. Acetate is the major precursor of fatty acid synthesis in adipose tissue of the cow (Bauman, 1976). Glucose is needed to provide reducing equivalents and as a source of glycerol for the production of triglycerides (Bauman, 1976). In the rumen of cows fed at the restricted level, in spite of similar $\mathrm{pH}$ and total VFA values, the percentage of acetate was lower and of propionate higher in thin cows than in fat cows and this was due respectively to a lower concentration of acetate and a higher concentration of propionate. In blood, however, there were no significant differences between fat and thin 

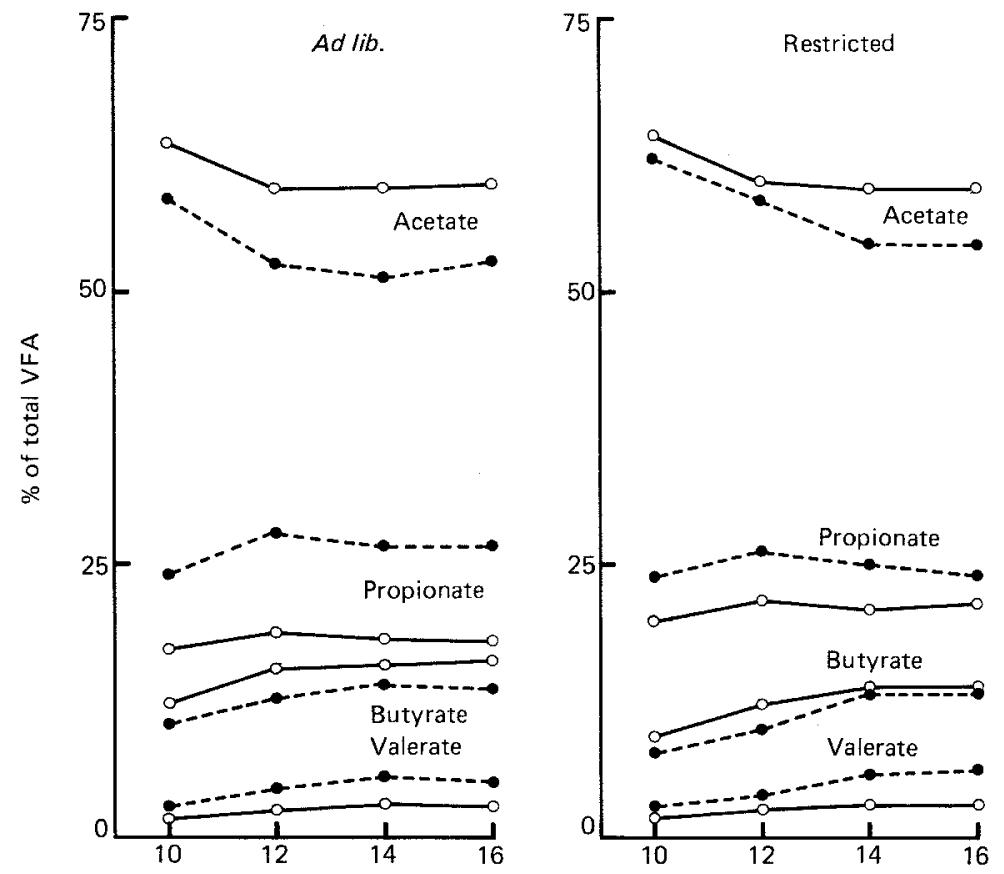

Period of feeding ( $h$ )

Fig. 2. The molar percentages of volatile fatty acids (VFA) before and after feeding in the rumen of six cows in fat (-) and thin (---) condition and on ad lib. and restricted diets.

Table 3. The concentrations (mmol/l) of metabolites in the blood plasma of six cows in fat and thin condition and on ad lib. and restricted rations

\begin{tabular}{|c|c|c|c|c|c|c|c|}
\hline & & \multicolumn{3}{|c|}{ Before feeding } & \multicolumn{3}{|c|}{ After feeding } \\
\hline & & Fat & Thin & SED & Fat & Thin & SED \\
\hline \multirow[t]{2}{*}{$3 \mathrm{HB}$} & Ad lib. & $0 \cdot 31$ & 0.23 & $0.065^{*}$ & 0.76 & 0.87 & $0 \cdot 121$ \\
\hline & Resticted & $0 \cdot 30$ & $0 \cdot 21$ & $0.058 \dagger$ & 0.64 & 0.70 & $0 \cdot 105$ \\
\hline \multirow[t]{2}{*}{ Acetate } & Ad lib. & $0 \cdot 73$ & 0.63 & 0.090 & $1 \cdot 57$ & $1 \cdot 73$ & 0.195 \\
\hline & Restricted & 0.72 & 0.57 & 0.033 & $1 \cdot 53$ & $1 \cdot 17$ & 0.205 \\
\hline \multirow[t]{2}{*}{ Propionate } & Ad lib. & 0.11 & $0 \cdot 11$ & 0.046 & $0 \cdot 16$ & $0 \cdot 26$ & 0.039 \\
\hline & Restricted & $0 \cdot 15$ & $0 \cdot 16$ & 0.025 & 0.20 & $0 \cdot 21$ & 0.010 \\
\hline \multirow[t]{2}{*}{ NEFA } & Ad lib. & 0.30 & $0 \cdot 18$ & 0.036 & $0 \cdot 18$ & $0 \cdot 15$ & 0.049 \\
\hline & Restricted & 0.25 & 0.17 & 0.024 & $0 \cdot 14$ & 0.08 & 0.020 \\
\hline \multirow[t]{2}{*}{ Glucose } & Ad lib. & $3 \cdot 89$ & 3.83 & 0.089 & $3 \cdot 32$ & 2.49 & 0.336 \\
\hline & Restricted & 3.94 & $3 \cdot 72$ & 0.072 & $3 \cdot 42$ & $2 \cdot 96$ & $0 \cdot 162$ \\
\hline
\end{tabular}

3HB, 3-hydroxybutyrate; NEFA, non-esterified fatty acids; SED, standard error of difference.

* SED, between fat and thin cows on the same or different rations: based on the error mean squares for cows $\times$ conditions $(5 \mathrm{df})$ and cows $\times$ rations within conditions $(4 \mathrm{df})$.

$\dagger$ SED between rations while the cows are in the same condition: based on the error mean square for cows $\times$ rations within conditions $(4 \mathrm{df})$.

cows in acetate or propionate concentrations, even though the relative concentration of acetate was lower in the thin cows than it was in the rumen. This was probably due to the small number of comparisons made at this level of intake and does not preclude the possibility that acetate utilization rate was higher in thin than in fat cows, enabling lower blood and rumen concentrations to be maintained in spite of probably similar production 

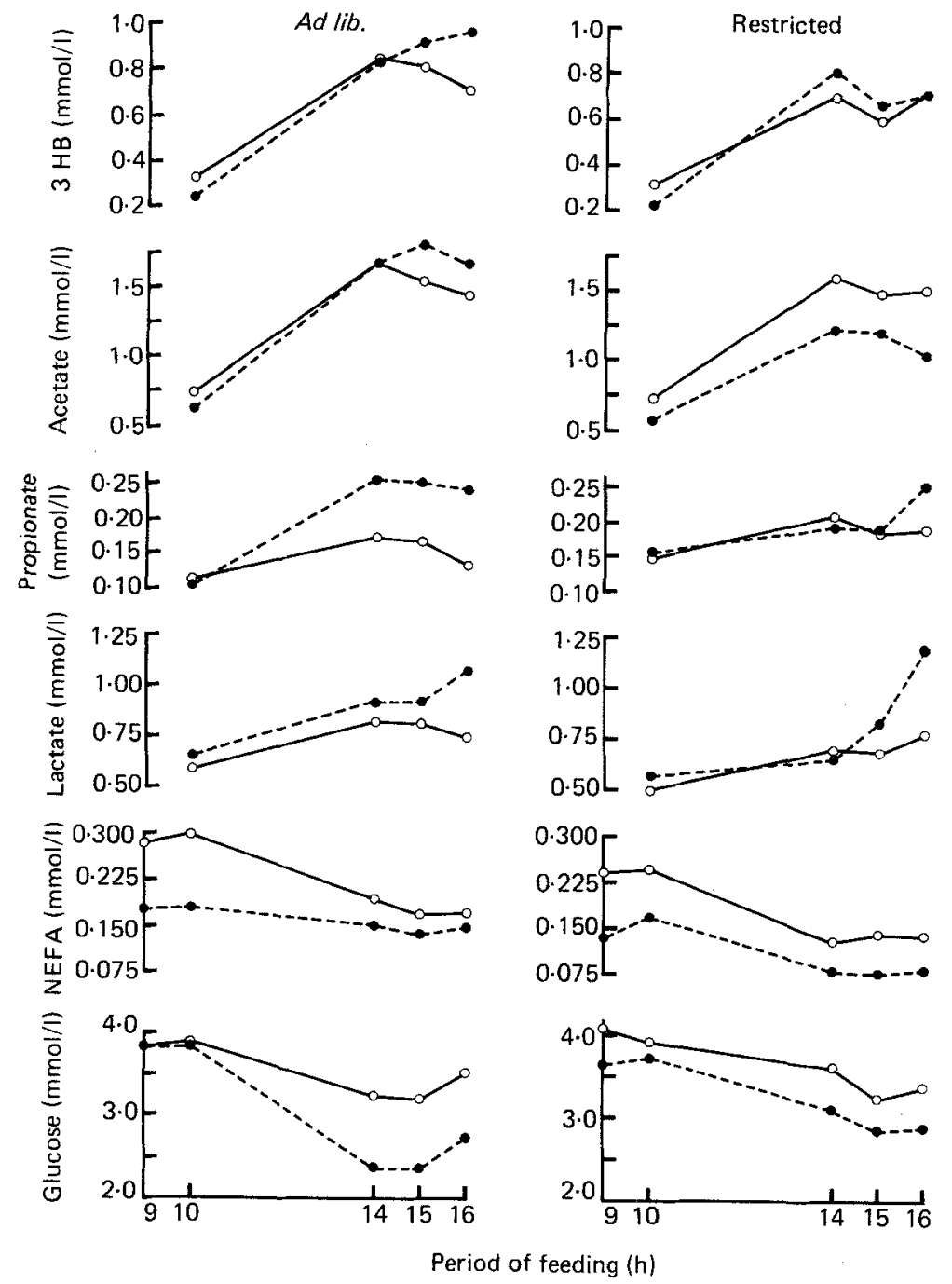

Fig. 3. The concentrations ( $\mathrm{mmol} / \mathrm{l}$ ) of metabolites in the blood plasma of six cows in fat $(\longrightarrow$ ) and thin (--) condition and on ad lib. and restricted diets. 3HB, 3-hydroxybutyrate, NEFA, non-esterified fatty acids.

rates of acetate. Although propionate concentrations were similar in both groups of cows in both rumen fluid and blood, plasma glucose concentrations were always lower in thin cows, suggesting a higher rate of utilization in this group. In view of the known requirement of glucose for lipogenesis, this observation is also compatible with the hypothesis. Orr (1977) has also observed higher blood glucose levels in fat sheep. Higher levels of NEFA in fat cows, especially before feeding, imply a greater rate of lipolysis in this group in response to energy deficit. This may be a reflection more of the availability of stored lipids for mobilization than of differences between the two groups of cows in hormonal response to energy deficit, but in the absence of hormonal measurements, this can only be speculation.

When the cows were fed ad lib. the $24 \%$ higher intake of the thin cows was reflected in a more rapid fall in rumen $\mathrm{pH}$ and a more rapid rise in total VFA concentration after feeding. The latter observation was attributable more to a higher prefeeding value in the fat cows than to a higher post-feeding value in the thin cows. The high prefeeding level of total VFA in fat cows was in turn attributable to higher levels of the lipogenic fatty acids, 
acetate and butyrate, which after feeding rose by similar amounts in both groups of cows in spite of the greater intake of the thin cows. In contrast, propionate rose more in the thin cows than in the fat cows. Similarly, in the blood, concentrations of both acetate and 3HB (which is derived largely from rumen butyrate) rose by similar amounts in both groups, whereas propionate level rose more in thin cows than in fat cows. This again is compatible with the hypothesis that the rate of utilization of lipogenic substrates, especially acetate, is higher in thin cows than in fat cows.

Blood glucose concentration, although similar in both groups of cows before ad lib. feeding, fell much more after feeding in the thin cows. This occurred in spite of a higher plasma concentration in the thin cows of propionate, the major precursor of glucose (Elliot, 1980). Presumably, therefore, there was a reduction in the rate of glucose synthesis or an increase in rate of utilization after feeding and this was relatively greater in thin cows than in fat cows. Glucose synthesis is thought to be controlled by glucagon, but little is known of factors influencing levels of this hormone in the cow. Propionate level in peripheral blood is known to play an important role in the control of secretion of insulin which, in turn, regulates glucose utilization (Bines et al. 1980). Thus the higher plasma propionate level in thin cows fed ad lib. may have resulted in a higher circulating level of insulin in that group. The fact that the decline in glucose level after feeding at the restricted level was similar in both groups of cows when plasma propionate levels were also similar supports this idea.

Elevated levels of insulin after a meal are also very important in the control of fat synthesis in adipose tissue (Bauman, 1976). However, it is possible that insulin: growth hormone (GH), rather than the absolute concentration of insulin, is critical in determining the net effect on adipose tissue (Rabinowitz et al. 1966; Forbes, 1980). Although the level of GH is reduced in obesity in man (Glass et al. 1981) there is no information on relative levels of GH in fat and thin cows. NEFA levels were much higher in fat cows before feeding and declined after feeding much more rapidly than in thin cows. This may imply that $\mathrm{GH}$ secretion falls more rapidly in response to feeding in fat cows or that adipocytes of fat cows are less sensitive to GH than those of thin cows. This may partly compensate for the increased insulin secretion assumed to occur in thin cows but, nevertheless, the net effect still appears to be in favour of enhanced net lipogenesis in the thin cows.

These observations, while not conclusive, are consistent with the stated hypothesis. The results give no indication of ways in which metabolism by adipose tissue may increase. Possibilities are: (1) increased availability of glucose or NADPH, (2) increased endocrine stimulation due to higher hormone levels or raised receptor sensitivity, (3) reduced inhibition, e.g. by accumulation of metabolic end-products. Any of these could operate either singly or in combination. Further work is required to clarify their relative roles and quantitative significance. Nevertheless, it is clear that the effect of body condition on food intake can probably be explained in terms of extension of short-term control mechanisms, rather than by needing to invoke a specific lipostatic (or long-term) control mechanism.

\section{REFERENCES}

Bauman, D. E. (1976). Federation Proceedings 35, 2308-2313.

Bines, J. A. (1971). Proceedings of the Nutrition Society 30, 116-122.

Bines, J. A. \& Davey, A. W. F. (1978). British Journal of Nutrition 39, 567-578.

Bines, J. A., Hart, I. C. \& Napper, D. J. (1980). Annual Report of the National Institute for Research in Dairying, p. 58. Reading: NIRD.

Bines, J. A., Suzuki, S. \& Balch, C. C. (1969). British Journal of Nutrition 23, 695-704.

Broster, W. H., Sutton, J. D. \& Bines, J. A. (1979). In Recent Advances in Animal Nutrition-1978, pp. 99-126 [W. Haresign and D. Lewis, editors]. London: Butterworths.

Elliot, J. M. (1980). In Digestive Physiology and Metabolism in Ruminants, pp 485-503 [Y. Ruckebusch and P. Thivend, editors]. Lancaster: MTP Press Ltd. 
Forbes, J. M. (1980). In Digestive Physiology and Metabolism in Ruminants, pp. 145-160 [Y. Ruckebusch and P. Thivend, editors]. Lancaster: MTP Press Ltd.

Glass, A. R., Burman, K. D., Dahms, W. T. \& Boehm, T. M (1981). Metabolism 30, 89-104.

Orr, R. M. (1977). A study on the role of body fatness in the control of voluntary feed intake in sheep. PhD Thesis, University of Edinburgh.

Rabinowitz, D., Merimee, T. J. \& Burgess, J. A. (1966). Diabetes 15, 905-910. 